\section{Weber y la política como vocación. Estudios y reflexiones a cien años de distancia ${ }^{*}$}

Agustín De Marco M $^{\text {A }}$

El verano europeo de 1919 vio surgir una de las obras capitales de la sociología, en general, y de la literatura weberiana, en particular. Se trata de La política como vocación, texto originado en la segunda de un par de conferencias dictadas por Max Weber (1864-1920) en Münich a la Libre Unión de los Estudiantes de Baviera. Las ideas contenidas en dicha ponencia pretendían guiar el trabajo intelectual de una juventud de posguerra sumamente consternada y movilizada. En su discurso, Weber no utilizó sino algunas notas escritas de su puño y letra para fines de organizar su alocución. Serían las notas taquigráficas las que, luego de ser organizadas y revisadas meticulosamente por el autor, darían lugar al texto tal como se conoce hoy en día.

El libro aquí reseñado remite a una serie de reflexiones con el objeto de llamar la atención sobre la fuerte vigencia de su contenido y su aplicación en la comprensión del mundo actual. Se trata de una compilación realizada por Israel Covarrubias -profesor investigador en la Facultad de Derecho de la Universidad Autónoma de Querétaro y Doctor en Ciencia Política por la Universidad de Florencia- en conjunto con Herminio Sánchez de la Barquera y Arroyo -Doctor en Ciencia Política por la Universidad de Heidelberg, Decano en Ciencias Sociales y profesor investigador en la Universidad Popular Autónoma del Estado de Puebla-.

Las seis contribuciones de las que se compone la obra se encuentran precedidas por un prólogo del politólogo alemán Dieter Nohlen, quien explica que el cambio en la percepción de la obra de Max Weber tuvo lugar a partir de un simposio realizado en la ciudad alemana de Heidelberg, el día 30 de abril de 1964, en conmemoración por el centenario de su nacimiento. En aquel evento, Talcott Parsons, Raymond Aron y Herbert Marcuse tuvieron a cargo las conferencias principales. Según lo indica Nohlen, fue esta oportunidad la que convirtió a Weber en un clásico de las ciencias sociales. Este autor reconoce la profunda influencia de la teoría de la ciencia weberiana en su propio quehacer científico e intelectual. Así, afirma que: "quien lee a Max Weber va a encontrar afirmaciones de importancia y de utilidad parecidas que le pueden guiar en sus estudios, así como simplemente inspirar a personas interesadas en la política” (p. XV). De este modo, e indicando la relevancia
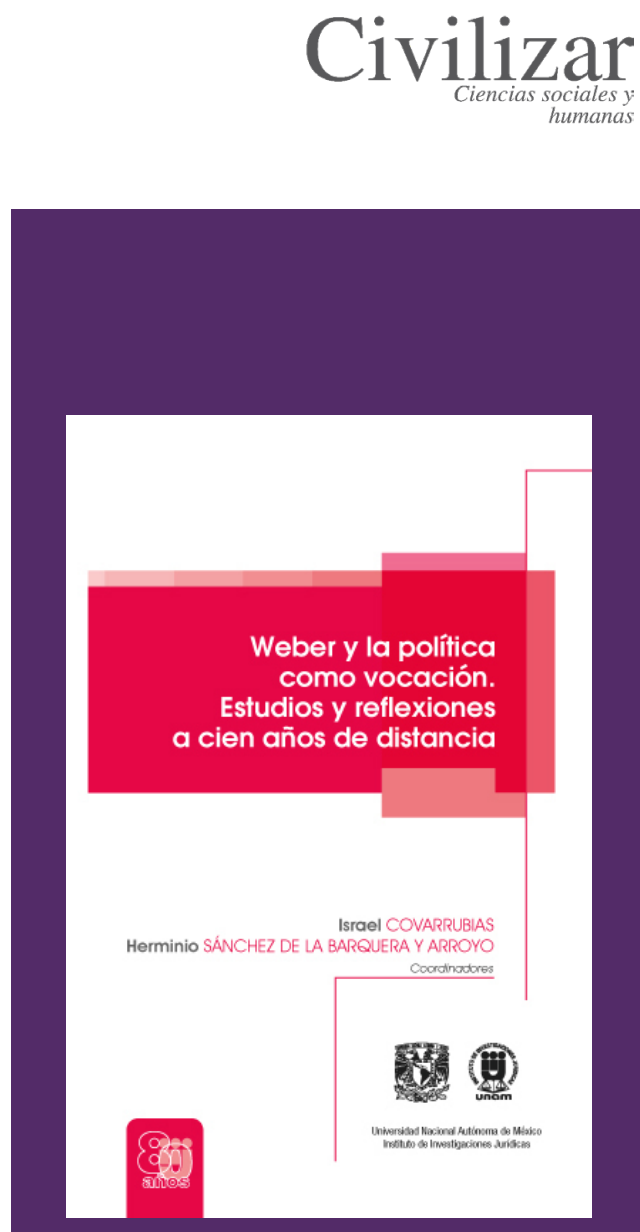

Reseña

Título original:

Weber y la política como vocación. Estudios y reflexiones a cien años de

distancia

Autores: Israel Covarrubias y Herminio Sánchez de la Barquera

y Arroyo (Coords.)

Año de publicación: 2020

Edición: Primera

Páginas: 153

ISBN: 978-607-303105-9

Editorial:

Instituto de Investigaciones

Jurídicas-UNAM

$\S$ Licenciado y profesor en Ciencia Política. Profesor ayudante de la cátedra de Comportamiento Político y Electoral, Universidad de Buenos Aires, Argentina.

Correo electrónico: agustindm.unlp@gmail.com. (iD) $0000-0003-1096-2927$ 
particular de La política como vocación, Nohlen invita a la lectura del libro de principio a fin.

Una vez concluido el prólogo, los compiladores se dirigen al lector con la intención de poner de manifiesto la importancia de revisitar el texto de la conferencia de cara a nuestro tiempo político, abrevando en las advertencias que Weber hizo sobre la (in)capacidad de los liderazgos políticos de responder de manera eficiente a los desafíos expresados por la sociedad. Los autores animan a pensar la noción de vocación en su doble acepción: por un lado, como un impulso hacia la acción y la decisión; por otro, como profesión propiamente dicha. La percepción generalizada de una falla sistémica en el funcionamiento de la (vocación) política erige la reflexión de los apartados subsiguientes, siempre en diálogo con el conjunto de la obra weberiana.

En La política como vocación, un estudio preliminar a cien años de distancia, Herminio Sánchez de la Barquera y Arroyo aborda el contexto de producción de la obra, así como los rasgos de la política en épocas de su autor. A su vez, incluye un breve apartado donde intenta esclarecer los tintes etimológicos germanos que llevan a traducir la palabra 'Beruf' a veces como ‘vocación' y otras como 'profesión'. El autor explica que Weber proclama la necesidad de objetividad y sobriedad en la política, lo cual podría ser realizado por los políticos de vocación más que por los políticos profesionales.

En lo sucesivo, Hernán Borisonik e Israel Covarrubias en su apartado El porvenir de la política como vocación se preguntan: ¿por qué hablar de política como vocación? Así pues, indagan acerca de los límites de la racionalidad y el actuar político e indican que Weber encuentra la respuesta al mejor orden social más en la arena política que en la ciencia. A su vez, estos autores enmarcan la relectura del texto weberiano en la comprensión de los desafíos actuales de la sociedad democrática para responder a las demandas por parte de los sectores menos favorecidos, quienes depositan expectativas (y esperanzas) acerca de los alcances y efectos de la política en su vida cotidiana.

Por su parte, Hugo César Moreno Hernández, en su texto Weber y Nietzsche: voluntad de poder $y$ asimetrías de la política, indaga acerca del componente volitivo del poder. A través de una base analítica nietzscheana, el autor destaca cuatro voluntades de poder como formas de actuar en la esfera política: el ciudadano, el cual se conforma a partir de la interiorización de la soberanía y cuyos intereses se hallan limitados por el derecho; el científico, un ciudadano con una vocación hacia el trabajo científico; el burócrata, quien realiza una función específica en un diseño operativo delimitado; y, por último, el político profesional, cuya voluntad de autoridad debe estar regida por el control de la propia vanidad -un autocontrol que deviene en la fuente de donde emana la autoridad pública-

Posteriormente, en el capítulo ¿Es posible pensar el populismo desde la obra de Max Weber?, Juan Cristóbal Cruz Revueltas realiza un estudio sobre las transformaciones recientes de la legitimidad democrática, así como sobre las nuevas formas de carisma. Además, reflexiona sobre el alcance del componente carismático en el surgimiento del populismo como expresión política. Este autor aduce que el liderazgo regido por el carisma no dependería de las cualidades ontológicas individuales, sino del hecho de que tal o cual líder sea considerado carismático en un contexto particular. De este modo, el líder carismático sería un líder situacional que se hace presente en un contexto de debilidad o de extrema rigidez institucional.

De otro lado, Verónica Yasmín García Morales estudia La ética de la responsabilidad de Weber en la política de seguridad. En esta sección, la autora analiza la ética de la convicción en relación con la libertad y la seguridad, al tiempo que aborda la política de seguridad urbana en el contexto de los derechos humanos. Asimismo, García Morales examina, desde la perspectiva weberiana que auspicia la responsabilidad y la mesura, la forma como actualmente se garantiza la seguridad en las ciudades. Para ello, parte de las premisas de que la seguridad es uno de los valores que mayor impacto tiene en la vida de las personas y que el Estado se halla inserto en una estructura de dominación donde los dominados deben acatar la autoridad.

Finalmente, Xavier Torrens analiza la gestión pública como profesión, haciendo especial énfasis en su cientificidad. En este apartado, llamado Entre Berufy Policy: más allá de la administración pública weberiana, Torrens indaga acerca de la nueva gestión pública posweberiana y realiza un pormenorizado análisis comparativo entre las características de la Administración Pública Tradicional y la Nueva Gestión Pública. El autor explica que la eficacia de un gobierno reside en la presencia de Beruf (lo vocacional o profesional) como componente inherente a 
la gestión pública. En ese marco, y abrevando en las bases teóricas de la administración weberiana, hoy en día se estaría tendiendo hacia una nueva gestión pública, aunque manteniendo en vigencia los criterios de formación especializada, profesionalidad y rigor técnico y metodológico.

El texto nodal que reúne e hilvana estas contribuciones coincidió con una etapa de intensos y acelerados procesos de demarcación y diversificación social, lo cual tuvo profundos efectos sobre la vida cotidiana y la organización institucional de las sociedades occidentales. La política como vocación posee un efecto de orden y orientación que le es propio y establece los moldes de comprensión de la acción y atribución de sentido propios de su tiempo. Más de 100 años después, la obra halla su eco en las profundas problemáticas que vienen a definir la vida política actual. La compilación aquí reseñada revisita los conceptos articulados en aquella conferencia de 1919 (y en la obra weberiana, en general), lo cual se revela de suma utilidad a la hora de intentar comprender -siempre con una mirada inquieta- los problemas políticos, sociales e institucionales de hoy en día. De allí, que la obra de Weber y sus aportes a la comprensión del mundo resistan, aún, el paso del tiempo. 